\title{
Meaning in the Process Of Signification by the Advertisement of Hot Ones and LEGO Movie 2
}

\author{
Andreas Dyka Terityus \\ English Department, Faculty of Languages and Literature, Petra Christian University, Siwalankerto \\ 121131, Surabaya 60236, INDONESIA \\ E-mail: m11415013@john.petra.ac.id
}

\begin{abstract}
This research aims to find meaning through the process of signification within the advertisement of Hot Ones and Lego Movie 2 by the use of verbal and visual expression. The focus of the analysis is the advertisement video. Using the process of signification, connotation, denotation and myth. These theories are used by the writer to analyze the meaning of the advertisement. Firstly, the writer finds meaning constructed in the advertisement. Then the writer discusses the findings. This research uses a descriptive qualitative method. Starting by compiling the data and transcribing the scenes into tables. The writer constructs meaning through verbal and visual data. Through the findings the writer found that meaning is created by the interaction of the characters. The index which was uncovered by using verbal and visual expression produces denotative and connotative meanings that are perceived by the audience as a myth.
\end{abstract}

Keywords: process of signification, myth, advertisement, LEGO, Hot Ones.

\section{INTRODUCTION}

In this study, the writer would like to analyze the Lego Movie 2 and Hot Ones promotional video. The promotional video entitled "LEGO Sean Evans Interviews Queen Watevra Wa'Nabi| Hot Ones" the promotional video follows two characters Sean Evans and Queen Watevra Wa'Nabi in an interview while eating spicy chiken wings. The writer focuses on the visual and verbal expression of the video. The purpose of the study is finding meaning within the advertisement.

The main theory that the writer used are process of signification, connotation, denotation and myth compiled by Daniel Chandler (2007). Process of signification is the process of identifying meaning in a form of a sign. sign is the smallest measurement of meaning, that can be found everywhere. In a form of television, books, movies, social media, etc. Each sign has a signifier, any material thing that signifies and signified, the concept that a signifier refers to (Chandler, 2007, p. 14). Dennotation is the most basic or literal meaning of a sign, e.g., the word "mouse" signifies a particular animal. While as, connotation is the secondary, cultural meanings of signs; or "signifying signs," signs that are used as signifiers for a secondary meaning, e.g., the word "mouse" signifies dirty or corrupt. Lastly, Myth by Roland Barthes ([1957] 1987). Myth is complicated. Myth is the combination of paradigmatic relations and syntagmatic relations. Paradigmatic relations is where signs get meaning from their association with other signs, e.g., "Red Car" means the car is bold and brave. Syntagmatic relations where signs get meaning from their sequential order, e.g., grammar or the sequence of events that make up a story. In short myth is a combination of paradigms and syntagms that make up an often told story with intricate cultural associations, e.g., the spy myth.

The explanation above raises the question about finding meaning within the advertisement through verbal and visual expression. Not only that, the writer also wanted to find the myth within the advertisement. 
Terityus: Meaning In the Process Of Signification by the Advertisement of Hot Ones and LEGO Movie 2

\section{METHOD}

This study the writer chose to use a descriptive qualitative approach to be used since the data are in the form of video. The video should be able to be interpreted from both verbal expression and visual. Furthermore, qualitative content analysis is used to analyze the meaning of a particular advertisement by describing its meaning in a systematic way.

The data is a form of promotional video. This promotional video is a collaboration between First We Feast and Warner Animation Group. The promotional video titled " $L E G O$ Sean Evans Interviews Queen Watevra Wa'Nabi| Hot Ones" which was uploaded on $29^{\text {th }}$ January 2019 and taken from First We Feast's YouTube channel. The source of the data was limited to the video that First We Feast uploaded. The promotional video advertisement is one minute and fifty seven seconds long, and it uses English language throughout the advertisement as the writer chooses to analyze several scenes of the advertisement both in verbal and visual.

The main instrument of this research is the writer himself as since the writer is the one who collects the data from the source, and the writer also the one who analyzed the data as well. The writer analyzes the promotional video of "LEGO Sean Evans Interviews Queen Watevra Wa'Nabi $\mid$ Hot Ones" on process of signification which involves connotation, denotation and myth. Before analyzing the data, the writer watched the video to understand the advertisement itself. After watching the video, the writer tries to transcribe the video in terms of speeches and actions that are in the video. The reason for transcribing is to make it simpler to analyze. Next, the writer took screenshots of the scenes for the analysis. The writer chooses all the scenes throughout the advertisement. Because the scenes are in sequence, one scene gives context to the next scenes. The writer then compiled the data, from the data the writer took the necessary scenes and took screenshots of the scenes. After the writer chooses the scenes the writer turns the chosen scenes to make a table. The table contains the time frames of the scenes, screenshots / photos of the scenes taken, visual expression and verbal expression After The writer finished compiling the data into tables, the writer proceeded to analyze the chosen scenes. In the next step, in order to answer the research questions, the writer analyzed the scenes in the promotional video from its verbal data and found its denotative meaning using the dictionary (Oxford Advanced Learner's Dictionary $8^{\text {th }}$ edition) to answer the first research question. Then, to connect the meaning from the verbal expression to the visual expression the writer uses process of signification to connect the textual and visual expressions. Lastly, in order to answer the last research question the writer explains the findings and concludes it.

\section{FINDINGS AND DISCUSSION}

The writer analyzed the data by watching the video from the beginning until the end, collected all data and then analyze it using the process of signification by Saussure (1974).

The writer analyzed all interaction beetween Sean Evans and Queen Watevra Wa'nabi. the writer procced to find meaning within those interactions using the visual and verbal data.

\section{The Visual and Verbal expression}

First of all, in each and every scene chosen, the writer explained the reason why it was chosen. Secondly, the writer analyzes the connotation and denotation of both verbal and visual expression to find the meaning. Next, the writer analyzed the connotation and denotation and connected the visual and verbal expression in the chosen scene. 
The interaction between both of the characters plays a huge role in creating meaning within the advertisement. The advertisement has a linear story line, where Sean Evans interviews Queen Watevra Wa'nabi while eating spicy chiken wings. The characters themself symbolizes their part in the advertisement. Sean Evans repersenting Hot Ones and Queen Watevra Wa'nabi representing The Lego Movie 2.

The writer first took notice that the visual expression used is in a form of Lego blocks. That in itself tells a story other than the linear story mentioned. The promotional video intentionally uses the Lego Blocks as another layer of marketing. Which is to market their Lego Toys product while as using it to promote the Lego Movie 2.

While focusing on the liner story. The writer found that Sean Evans is a good interviewer and Queen Watevra Wa'nabi suits her name. As indicated by their choices of words, interactions and actions.

\section{The Myth Within the Advertisement.}

The writer thinks that this advertisement has a hidden agenda. as a form of capitalism, packaged for the adults and the children. One it promotes Lego as the toymaker brand by using the literal lego blocks to advertise the whole part of the advertisement. And the other is it promotes Lego movie 2 by using the Queen Wateva Wa'nabi in the advertisement. But it has deeper naturalization than that. The writer strongly believes that this advertisement is a new form of guerrilla marketing. One that not only sells one product, but two. Using pop culture as a vehicle of advertisement. We take the advertisement as just one of the usual episodes of Hot Ones.

Referring to one of Barthes's topics in mythologies (1970, p54) “Toys". In Toys, Barthes mentions that french toys are meant to be a mold for the children and it does fulfill that role . Because in the passage ".. french toys literally prefigure the world of adults functions.." through the use of toys that symbolizes adult life. From toy guns to toy soldiers etc. yet in this study. Not only, Lego a company not only able to induce creativity to people of all ages by using their Lego Toy, but also they are able to break through their own mold as a toymaker to become a cultural icon of creativity. Lego Company adding a way to how their product is perceived by the consumer from having to sell toys to making films using their toys. That act itself is a feat.

The lego product in itself is the myth. As now we take the lego products as a character of its own as shown by Queen Wateva Wa'nabi. Disregarding that fact that the Queen is made up of a couple blocks of lego bricks. Yet, we knew that combination of that specific lego blocks from its color to its facial properties, we knew that it is Queen Wateva Wa'nabi. Lego Company being able to naturalize the index of a toy of its plastic properties to becoming an icon of a movie. Giving life and meaning to mere blocks of plastic that have a laser printed face on it. In the end, we all knew Lego's sole purpose of doing this branching of the market is to without a doubt recycle its way to sell more Lego products.

\section{CONCLUSION}

The writer acknowledges that promotional video advertisements consist of visual and verbal expressions. In the sense of visual and verbal expression go hand in hand to create meaning for it is easier for the audience to perceive. To uncover meaning, the use of process of 
Terityus: Meaning In the Process Of Signification by the Advertisement of Hot Ones and LEGO Movie 2

signification is the best method. Next the writer formulates the research question to be answered. The questions are how meaning is created through Verbal and visual expression and the second one is how myth operates within the advertisement. To answer the research question the writer uses a descriptive qualitative method to uncover meanings within the advertisement, therefore the writer himself is the instrument of the research. The data used are LEGO Sean Evans Interviews Queen Watevra Wa'Nabi | Hot Ones taken from Hot Ones youtube channel as a collaboration of Hot Ones and Lego company. In order to uncover the meaning behind the advertisement not only that the writer uses process of signification but also connotation, denotation and myth. With codes as a supporting theory. The writer finds the relationship throughout the advertisement.

In the findings, the writer found a meaning behind the expression uttered by the two characters within the advertisement. From Sean Evans, the writer notices his traits are the same as Hot Ones as a web series. As well as Queen Watevra Wa'nabi as that represents Lego Movie 2.

In verbal expression the utterances are intertwined with the visual because the connection that it creates is in depth meaning far more than the advertisement suggests.

The Myth that the writer found was that the Lego company creates its own myth by emptying its index of being a toymaker company to becoming a cultural icon of creative toys. The company has established their own perceivable meaning towards the brand by the branching. The branching has created pop culture icons using films with the vehicle of using Lego Blocks as the visual media.

In conclusion, the analysis of the data "LEGO Sean Evans Interviews Queen Watevra Wa'Nabi $\mid$ Hot Ones' ' is the visual and verbal product of the characters within the advertisement. The meaning was obtained from directly connecting to a series of meanings uttered by the characters and connecting the shows represented to the accordance of the characters mentioned. In which it was natulizing the index given by the meaning grasped. Understanding how meaning is created in advertisements will surely help in creating a powerful and precise advertisement.

\section{REFERENCES}

Barthes, R. (1977). Image-Music-Text. London: Fontana.

Chandler, D. (2007). Semiotics The Basics (2nd ed). London: Routledge.

Einwächter, S. G. \& Simon, F. M. (2017). How Digital Remix and Fan Culture Helped The Lego Comeback. Germany: Philipps-Universität Marburg. United Kingdom: University of Oxford.

Saussure, F. (1974). Course in General Linguistics. London:Fontana

Wibowo, J.H Nicholas. (2016). Meaning in the process of signification by the advertisement of Honda Surabaya: Petra Christian University. 